\title{
Cimetidine Does Not Prevent Lung Injury in Newborn Premature Infants
}

\author{
ROBERT B. COTTON, TOM A. HAZINSKI, $\dagger$ JASON D. MORROW, L. JACKSON ROBERTS, DARRYL C. ZELDIN, \\ DANIEL P. LINDSTROM, URPO LAPPALAINEN, AMY B. LAW, AND STEVEN STEELE
}

\begin{abstract}
Departments of Pediatrics and Medicine [R.B.C., T.A.H., J.D.M., L.J.R., D.P.L., U.L., A.B.L., S.S.], Vanderbilt University, Nashville, Tennessee 37232; National Institutes of Health/National Institute of Environmental Health Sciences [D.C.Z], Research Triangle Park, North Carolina, 27709
\end{abstract}

\begin{abstract}
Animal studies have shown that induction of cytochrome P450 (CYP) in the lung by oxygen exposure may result in the release of free radical oxidants and arachidonic acid metabolites, which can cause lung injury that is reduced by treatment with cimetidine, a CYP inhibitor. To determine whether cimetidine would reduce lung injury in human infants at risk for chronic lung disease, we conducted a randomized clinical trial in which we administered either cimetidine or a placebo for $10 \mathrm{~d}$ beginning $<24 \mathrm{~h}$ after birth to 84 newborn infants weighing $\leq 1250 \mathrm{~g}$ who were receiving $\mathrm{O}_{2}$ and mechanical ventilation. Cimetidine had no significant effect on severity of respiratory insufficiency assessed at $10 \mathrm{~d}$ postnatal age. $\mathrm{F}_{2}$-isoprostane levels (a marker of oxidant injury) in tracheal aspirates were significantly higher in the cimetidine group at $4 \mathrm{~d}$ and at $10 \mathrm{~d}$. There were no significant differences between the groups in tracheal aspirate levels of inflammatory markers (leukotriene $\mathrm{B}_{4}$, IL-8, and nucleated cell count) or arachidonic acid metabolites. We conclude that cimetidine does not reduce lung injury in newborn premature infants receiving $\mathrm{O}_{2}$ and mechanical ventilation. It is possible that cimetidine was not an adequate CYP inhibitor in this context. (Pediatr Res 59: 795-800, 2006)
\end{abstract}

$\mathrm{C}$ imetidine, a cytochrome P450 (CYP) inhibitor as well as an $\mathrm{H}_{2}$ blocker, prevents the severe pulmonary gas exchange failure that occurs in newborn lambs after $72 \mathrm{~h}$ of breathing $95 \%$ oxygen (1). It is postulated that this beneficial effect occurs as a result of the inhibitory action of this drug on CYP metabolism in the lung, since this enzyme system, which is induced by oxygen exposure, can be a source of free radical oxidants and specific metabolites of arachidonic acid that have the potential to cause lung injury (2).

There is a variety of in vivo evidence to support the concept of CYP mediated oxidant injury. For example, survival of newborn rats in $100 \% \mathrm{O}_{2}$ is significantly decreased by treatment with 3-methylcholanthrene, an inducer of the 1A1 isoform of CYP in the lung (3). Treatment with IL-1, which prolongs the survival of rats exposed to lethal concentrations

Received November 1, 2005; accepted February 1, 2006.

Correspondence: Robert B. Cotton, M.D., Department of Pediatrics, Vanderbilt University Medical Center, 11111 Doctor's Office Tower, 2200 Children's Way, Nashville, TN 37232-9544; e-mail: robert.cotton@vanderbilt.edu

+ Deceased.

Supported by HL56697, GM42056, GM15431, and DK26657 from the National Institutes of Health and by the Intramural Research Program of the National Environmental Health Services Division, National Institutes of Health.

DOI: $10.1203 / 01 . p d r .0000219397 .35473 .5 f$ of $\mathrm{O}_{2}$, also results in a significant decrease in pulmonary CYP, a decrease of CYP 2B1 isoform mRNA, and a significant decrease in superoxide anion generation from isolated pulmonary microsomes (4). In a rabbit model of lung reperfusion injury, CYP inhibitors (including cimetidine) markedly decrease lung edema and prevent the reperfusion-related increase in lung microvascular permeability (5). In an isolated perfused rat heart model, cimetidine and other CYP inhibitors confer a dose-dependent reduction in myocardial damage following ischemia and reperfusion, an effect attributed to suppression of reactive oxygen species production (6). Carbon tetrachloride liver injury is known to be mediated by a CYPcatalyzed reaction that produces free radicals. In rats exposed to carbon tetrachloride, inhibition of CYP has been shown to decrease hepatic lipid peroxidation (7). There are strains of mice that differ in regard to whether their lung CYP is inducible by oxygen. Oxygen toxicity is greater in those strains with oxygen-inducible CYP (8). Finally, cimetidine does not protect against oxygen toxicity in rats that do not show induction of CYP by oxygen $(9,10)$. This would suggest that the induction of CYP activity by oxygen is essential for its role in mediating oxygen toxicity.

The CYP system comprises numerous isoforms of this microsomal mixed function monooxygenase, which are distributed across a variety of tissues and organs $(11,12)$. Among the several functions of this system is the "third pathway" conversion of AA to the epoxide and hydroxyl derivatives, EET, and hydroxyeicosatetraenoic acids, respectively, which mediate a variety of biologic actions that could lead to lung injury (13-15). Newborn premature infants with lung disease requiring oxygen therapy have evidence of increased pulmonary CYP activity in that their tracheal aspirates have elevated levels of certain EET derivatives compared with infants not requiring oxygen therapy (unpublished data).
Abbreviations: AA, arachidonic acid; CLD, chronic lung disease; CYP, cytochrome P450; EET, epoxyeicosatrienoic acid; IVH, intraventricular hemorrhage; $\mathbf{L T B}_{\mathbf{4}}$, leukotriene $\mathrm{B}_{4}$; PDA, symptomatic patent ductus arteriosus; PMA, postmenstrual age; RII, respiratory insufficiency index; TA, tracheal aspirate 
This report gives the results of a clinical trial designed to test the hypothesis that cimetidine, by reducing both free radical oxidant generation and the production of CYPdependent AA metabolites in the lung, would reduce early lung injury in premature human infants at risk for CLD. In this trial, lung injury was evaluated using a clinical index based on the inspired oxygen concentration and intensity of mechanical ventilation. $\mathrm{F}_{2}$-isoprostanes in tracheal aspirate fluid were used as a marker of lipid peroxidation resulting from free radical oxidant generation. TA concentrations of certain EETs were used to assess CYP activity in the airway. The involvement of inflammatory mechanisms was assessed by the nucleated cell count and levels of IL-8 and LTB 4 in TA fluid.

\section{METHODS}

This was a randomized, double-blind, placebo-controlled trial that was reviewed and approved by the Vanderbilt Institutional Review Board. In this trial, a 10-d intravenous infusion of either cimetidine or saline placebo was given beginning 12-24 h after birth. Inclusion and exclusion criteria are shown in Table 1 .

The trial was conducted in a single-center newborn intensive care unit that provided neonatal care for 950 admissions annually (58\% inborn) in 24 intensive care beds and 24 intermediate care beds. Survanta was used for surfactant replacement treatment of hyaline membrane disease in a rescue mode according to the package insert. A single dose of prophylactic indomethacin $(0.2 \mathrm{mg} / \mathrm{kg})$ was given to infants with a birth weight $<1250 \mathrm{~g}$ who were dependent on mechanical ventilation at $24 \mathrm{~h}$ after birth. Dexamethasone was given to infants with severe, life-threatening ventilatory failure due to developing or established CLD, but not before 2 wk postnatal age. Methylxanthine therapy was used for clinically significant apnea of prematurity but was not used preemptively when mechanical ventilation was discontinued. Study patients received vitamin A supplementation according to protocol (16).

The diagnosis of hyaline membrane disease was based on clinical and radiographic findings. Symptomatic PDA was diagnosed according to previously published criteria (17). Criteria for a diagnosis of CLD at $28 \mathrm{~d}$ postnatal age included an oxygen requirement, abnormal chest physical examination (tachypnea or retractions or rales), and an abnormal chest radiograph with findings compatible with CLD. A diagnosis of CLD at $36 \mathrm{wk}$ PMA, intended to include infants with "new bronchopulmonary dysplasia," was based on a chronic $\mathrm{O}_{2}$ requirement in infants at 36 wk PMA who had a diagnosis of CLD at $28 \mathrm{~d}$ postnatal age. IVH was diagnosed by cranial ultrasonography carried out at 7 and $30 \mathrm{~d}$ postnatal age and at other times if clinically indicated. Grades of IVH were based on published criteria (18). Diagnoses of retinopathy of prematurity, necrotizing enterocolitis, and sepsis were made on clinical grounds.

Table 1. Inclusion and exclusion criteria

- Postnatal age between 12 and $24 \mathrm{~h}$

- Birth weight between 500 and $1250 \mathrm{~g}$, inclusive

- Gestational age $<32$ wk (i.e., not severely growth retarded)

- Ventilator dependent at the time of randomization

Exclusion criteria

- Any major congenital anomaly

- Moribund ("do not resuscitate" status, or request for this status under discussion with family)

- Acute life-threatening cardiorespiratory failure $\left(\mathrm{PaO}_{2}<5.3 \mathrm{kPa}\right.$ or $\mathrm{PaCO}_{2}$ $>9.3 \mathrm{kPa}$ or base deficit $>15 \mathrm{mEq} / \mathrm{L}$ documented by most recent blood gas analysis)

- Hypoplastic lungs (radiographic evidence of reduced lung volume with peak inspiratory pressure $30 \mathrm{~cm} \mathrm{H}_{2} \mathrm{O}$ plus $\mathrm{PaO}_{2}<6.6 \mathrm{kPa}$ or $\mathrm{PaCO}_{2}$ $>8.0 \mathrm{kPa}$ plus associated in utero context of prolonged oligohydramnios or fetal hydrops)

- Hydrops fetalis

- Lack of informed parental consent
The primary outcome variable was severity of lung disease at $10 \mathrm{~d}$ of age assessed using an RII. RII was calculated as the product of $\mathrm{FIO}_{2}$ and mean airway pressure multiplied by 100 . Secondary pulmonary outcomes included the RII on study d 4, duration of mechanical ventilation and oxygen therapy, CLD at 28 d postnatal age and at 36 wk PMA, and alive without CLD at either 28 d postnatal age or 36 wk PMA. Other secondary outcomes included TA cell counts and levels of selected EETs, $\mathrm{F}_{2}$-isoprostanes, IL-8, and $\mathrm{LTB}_{4}$ obtained on study d 1,4 , and 10 .

The study time line for cimetidine/placebo treatment, sample collection, and other events is shown in Table 2. A final assessment of clinical outcomes was made at 36 wk PMA. Length of hospital stay was based on the day when the infant was discharged home.

All admissions to the NICU were screened by two research nurses (A.B.L. and S.S.) to identify candidates for study entry and to ask for written informed consent from the parent(s) of those who met study entry criteria. The research nurses also supervised the administration of the study drug, obtained and processed blood and tracheal aspirate specimens as called for by the protocol, and recorded pertinent clinical and laboratory data on a concurrent basis. All data were entered into a Microsoft Access database designed by one of the authors (D.P.L.).

Cimetidine was infused intravenously for $10 \mathrm{~d}$ at a rate of $0.5 \mathrm{mg} / \mathrm{kg} / \mathrm{h}$ following a loading dose of $2.374 \mathrm{mg} / \mathrm{kg}$. This dose was calculated to provide a steady state plasma level of $2.5 \mu \mathrm{g} / \mathrm{mL}$ based on published pharmacokinetic data related to its use as an $\mathrm{H}_{2}$ blocker (19-21). This plasma level also appears to provide effective CYP inhibition in that it has been shown to reduce theophylline clearance significantly in adults (personal communication, Dr. K.V. Speeg, University of Texas Health Science Center, Galveston, TX). Plasma levels of the drug required to cause CYP inhibition in newborn premature infants are not known. The Vanderbilt Pediatric Pharmacy dispensed the study drug (cimetidine or normal saline placebo, labeled as "study drug") according to random allocation tables maintained by the pharmacy director. Plasma concentration of cimetidine was measured (22) from a blood sample drawn $24 \mathrm{~h}$ after beginning the drug.

An enrollment of 288 patients (144 in each group) was planned to occur over a period of $48 \mathrm{mo}$. These sample sizes were sufficiently large to detect a change in the RII at study d 10 of $26 \%$ with a $p$ value $<0.05$ and $80 \%$ power. Treatment was randomly allocated using block randomization according to weight (three strata: 500-749 g, 750-999 g, 1000-1249 g) and gender (two strata). An oversight committee including two neonatologists, a biostatistician, and a data analyst was formed to monitor efficacy and safety at 6,12 , 24, and 36 mo after enrollment began.

TA fluid was obtained by the instillation of $0.5 \mathrm{~mL}$ of normal saline through a catheter advanced just beyond the tip of the endotracheal tube followed by aspiration. Each TA fluid sampling session involved four instillation/aspiration events separated by $15-30 \mathrm{~s} ; 44 \pm 14 \%$ of the $2 \mathrm{~mL}$ of instilled saline was recovered.

$\mathrm{F}_{2}$-isoprostanes and CYP AA metabolites (8,9-, 11,12-, and 14,15-EET) were measured in TA fluid with an assay employing stable isotope dilution techniques utilizing negative ion chemical ionization-gas chromatographymass spectrometry $(23,24)$. IL-8 in TA fluid was assayed using a commercially available ELISA kit ( $\mathrm{R} \& \mathrm{D}$ Systems, Minneapolis, MN). $\mathrm{LTB}_{4}$ was assayed using a Biotrak enzyme immunoassay EIA system (Amersham, Aylesbury, UK).

Statistical methods. Categorical variables were compared between groups using Pearson $\chi^{2}$ analysis or Fisher's exact test when the value in a cell was less than 5. Group differences between skewed variables such as TA fluid markers and duration of respiratory support and hospital stay were analyzed using the Kruskal-Wallis method, which is the nonparametric analog of the two-sample $t$ test. The two-sample $t$ test was used to test group differences between other variables. Changes over time of tracheal aspirate markers were assessed using repeated measures ANOVA after logarithmic transformation of the data to reduce skewness.

Table 2. Study time line

\begin{tabular}{|c|c|c|c|}
\hline Event & Tim & e (postnatal days) & \\
\hline Study day (d 1 begins at & $\begin{array}{lll}1 & 2 & 3\end{array}$ & $\begin{array}{llllll}4 & 5 & 6 & 7 & 8 & 9\end{array}$ & 10 \\
\hline mize & $X$ & & \\
\hline $\mathrm{d}$ for $\mathrm{F}_{2}$-is & $X$ & $\mathrm{X}$ & \\
\hline lacebo $(\mathrm{c}$ & X X X & $X X X X X X$ & $\mathrm{X}$ \\
\hline metidine level & $\mathrm{X}$ & & \\
\hline Collect TA fluid for CYP A & & $\mathrm{X}$ & \\
\hline A fluid for inf & $\mathrm{X}$ & $X$ & \\
\hline Assess RII & $X$ & $\mathrm{X}$ & \\
\hline
\end{tabular}


A $p$ value $<0.05$ was considered statistically significant. Data analysis was carried out using Systat Version 8 (Systat Software, Richmond, CA).

\section{RESULTS}

Enrollment into this trial was stopped on the recommendation of the oversight committee after 84 study patients had been admitted. This action was taken because of concern surrounding the finding of increased incidence of death or severe IVH, and because statistical analysis indicated that there would be less than a $4 \%$ chance of detecting a difference in the primary outcome variable if the study were continued until enrollment was complete at 288 patients. When enrollment was stopped, 41 patients had been admitted to the cimetidine group and 43 had been admitted to the placebo group. Baseline clinical characteristics of the patients in the two groups are shown in Table 3. There were no statistically significant differences between the groups in any of a variety of attributes that are commonly associated with susceptibility to lung injury or CLD. A clinical diagnosis of acute chorioamnionitis was made in the perinatal period in only two patients in the cimetidine group and three in the placebo group. Histologic findings of the placenta and membranes were not available for analysis.

There was no difference between groups in the primary outcome variable, RII assessed on study d 10 (Table 4).

There were no differences between groups in the secondary outcomes shown in Table 4 including RII on study d 4, duration of mechanical ventilation, duration of oxygen therapy, and incidence of CLD at $28 \mathrm{~d}$ postnatal age or at $36 \mathrm{w}$ PMA. There were also no differences in those alive without CLD at either $28 \mathrm{~d}$ postnatal age or 36 wk PMA.

Adverse outcomes that were assessed are shown in Table 5. There were no statistically significant differences between the groups in IVH (any grade or severe), death, retinopathy of prematurity requiring laser treatment, necrotizing enterocolitis, highest serum total bilirubin beyond $10 \mathrm{~d}$ postnatal age, PDA requiring indomethacin or ligation, or days in the hospital. The cimetidine group did have a significantly increased incidence of death or severe IVH, 37\% versus $9 \%, p<0.01$.

Table 3. Baseline clinical characteristics

\begin{tabular}{|c|c|c|}
\hline & $\begin{array}{l}\text { Cimetidine } \\
(n=41)\end{array}$ & $\begin{array}{l}\text { Placebo } \\
(n=43)\end{array}$ \\
\hline Birth weight (g) & $850 \pm 223$ & $862 \pm 210$ \\
\hline Gestational age (wk) & $26.6 \pm 1.8$ & $27.0 \pm 2.0$ \\
\hline Inborn & $32(78)$ & $34(79)$ \\
\hline Male & $22(54)$ & $23(53)$ \\
\hline African American & $10(24)$ & $7(16)$ \\
\hline Ruptured membranes $>24 \mathrm{~h}$ & $6(15)$ & $10(23)$ \\
\hline Antepartum corticosteroid treatment & $28(68)$ & $27(63)$ \\
\hline Apgar score at $1 \mathrm{~min}$ & $4.0 \pm 2.4$ & $3.9 \pm 2.2$ \\
\hline Apgar score at $5 \mathrm{~min}$ & $5.5 \pm 2.3$ & $5.4 \pm 1.9$ \\
\hline Hyaline membrane disease & $37(90)$ & $38(88)$ \\
\hline RII & $408 \pm 211$ & $476 \pm 262$ \\
\hline $\mathrm{FIO}_{2}$ & $0.49 \pm 0.18$ & $0.54 \pm 0.19$ \\
\hline Surfactant treatment & $37(90)$ & $39(91)$ \\
\hline
\end{tabular}

None of the differences between groups is statistically significant. Results are expressed as either mean $\pm \mathrm{SD}$ or $n(\%)$.
The results of TA fluid analyses are shown in Table 6 . There was no difference between the groups in tracheal aspirate levels of $\mathrm{F}_{2}$-isoprostanes at baseline, but this marker was significantly higher in the cimetidine group than in the placebo group on study d 4 and 10 . No significant difference was seen in the level of EETs in tracheal aspirate fluid on study d 4 . There were no significant differences in TA fluid levels of the inflammatory markers (IL-8, $\mathrm{LTB}_{4}$, or nucleated cell count) on any day that a sample was taken.

The data in Table 6 were also analyzed using repeated measures ANOVA. For both groups combined, there was a significant decrease $(p<0.001)$ over time in tracheal aspirate levels of $\mathrm{F}_{2}$-isoprostanes and $\mathrm{LTB}_{4}$ and a significant increase $(p<0.001)$ over time in TA levels of IL-8 with and without adjustment for study group assignment (data not shown). There was no significant change over time in TA nucleated cell count. The decrease over time in $\mathrm{F}_{2}$-isoprostanes was less in the cimetidine group than in the placebo group, but this difference was only marginally significant $(p=0.078)$ in this analysis. No significant effect of cimetidine treatment was seen over time in the other tracheal aspirate markers.

Plasma cimetidine concentration $24 \mathrm{~h}$ after beginning the drug infusion was $3.84 \pm 1.59 \mu \mathrm{g} / \mathrm{mL}$ (mean $\pm \mathrm{SD}, n=40$ ).

\section{DISCUSSION}

Cimetidine had no beneficial effect in this trial on the severity of early lung injury in premature infants receiving mechanical ventilation and oxygen therapy. In addition, cimetidine did not reduce markers of oxidant injury, CYP activity, or inflammation in the airway of these infants.

There is a variety of explanations why no beneficial effect of cimetidine was seen. EET levels in TA fluid were not reduced in the cimetidine group compared with the placebo group, implying that CYP activity may not have been adequately inhibited. Even though cimetidine treatment clearly inhibits CYP 2B1 activity in lung microsomes of lambs exposed to high oxygen concentrations (1), not all CYP isoforms are inhibited by cimetidine (25) and there is considerable variation between laboratory animals and humans in the distribution of isoforms (12). It is possible that CYP isoforms that are not inhibited by cimetidine provided a source of EET production and oxidant release in the human infants enrolled in this trial.

Other explanations why no beneficial effect of cimetidine was seen in this study came to light after the trial was underway. Increased CYP activity does not necessarily lead to cell injury, and in some cases may have a protective effect. For example, transgenic mice with cardiomyocyte-specific overexpression of CYP2J2 have improved recovery of left ventricular function compared with wild-type hearts after ischemia-reperfusion injury (26). Certain EETs have been shown to have anti-inflammatory properties including decreased cytokine-induced endothelial cell adhesion molecule expression and decreased leukocyte adhesion to the vascular wall (27). In adult male rats, oxygen-mediated lung injury is not reduced, but aggravated by treatment with 1-aminobenzotriazole, a CYP inhibitor that is effective against the major pulmonary 
Table 4. Primary and secondary outcomes

\begin{tabular}{lccc}
\hline \multicolumn{1}{c}{ Primary outcome } & Cimetidine $(n=41)$ & Placebo $(n=43)$ & $p$ Value \\
\hline RII on study d 10 & $248 \pm 223(n=37)$ & $229 \pm 231(n=41)$ & \\
$\quad$ Secondary outcomes & $224 \pm 183(n=39)$ & $200 \pm 197(n=41)$ \\
RII on study d 4 & $25(2-78)(n=34)$ & $18(1-59)(n=39)$ & 0.578 \\
Days of mechanical ventilation* & $55(2-84)(n=34)$ & $50(2-92)(n=39)$ & $7(0-51)(n=39)$ \\
Days with $\mathrm{FIO}_{2}>0.21^{*}$ & $12.5(1-75)(n=34)$ & $28 / 39(72)$ & 0.104 \\
Days with $\mathrm{FIO}_{2}>0.4^{*}$ & $25 / 35(71)$ & $19 / 39(49)$ & 0.465 \\
CLD at 28 d postnatal age $\dagger$ & $14 / 34(41)$ & $11 / 43(26)$ & 0.972 \\
CLD at 36 wk PMA* & $10 / 41(24)$ & $19 / 43(44)$ & 0.900 \\
Alive, no CLD at 28 d postnatal age & $20 / 41(49)$ & 0.673 \\
Alive, no CLD at 36 wk PMA & &
\end{tabular}

There are no significant differences between the groups. Results are expressed as mean $\pm \mathrm{SD}$, median (range) or $\mathrm{n} /$ total $(\%)$.

* Among survivors at 36 wk PMA.

$\dagger$ Among survivors at $28 \mathrm{~d}$ postnatal age.

Table 5. Other outcomes

\begin{tabular}{lcc}
\hline & $\begin{array}{c}\text { Cimetidine } \\
(n=41)\end{array}$ & $\begin{array}{c}\text { Placebo } \\
(n=43)\end{array}$ \\
\hline Grade 1-4 IVH & $19(46)$ & $12(28)$ \\
Grade 3-4 IVH & $9(22)$ & $3(7)$ \\
Death by 36 wk PMA & $7(17)$ & $4(9)$ \\
Death (36 wk) or grade 3-4 IVH & $15(37)^{*}$ & $4(9)$ \\
Retinopathy of prematurity requiring & $1(3)$ & $2(5)$ \\
$\quad$ laser treatment $\dagger$ & & \\
Necrotizing enterocolitis & $2(5)$ & $3(7)$ \\
Highest total bilirubin $>10 \mathrm{~d}$ & $7.3 \pm 2.4$ & $5.9 \pm 3.9$ \\
$\quad$ PMA (mg/dL) $\dagger$ & $18(53)$ & $21(54)$ \\
Sepsisं \\
Antibiotic treatment $\geq 7 \mathrm{~d} \dagger$ \\
PDA treated with indomethacin & $31(91)$ & $31(79)$ \\
$\quad$ or ligation & $12(29)$ & $6(14)$ \\
Days in hospital $\ddagger$ & $75(32-168)$ & $73(0-326)$ \\
\hline
\end{tabular}

Results are expressed as $n(\%)$, mean $\pm \mathrm{SD}$, or median (range).

$* p<0.01$ compared with placebo group.

$\dagger$ Among survivors at 36 wk PMA (cimetidine: $n=34$; placebo: $n=39$ ).

$\ddagger$ Total number of days of entire hospital stay among infants alive at $36 \mathrm{wk}$ PMA.

isoforms (28). In rats, hyperoxic induction of hepatic CYP1A1 and $1 \mathrm{~A} 2$ activities is only transient, and has diminished to baseline levels by the time clinical and histologic evidence of lung injury is well established (29). Adult male rats pretreated with the CYP1A inducer beta-naphthoflavone have less pleural effusion following $>95 \%$ oxygen exposure than untreated rats (30), a finding that also supports the concept of a protective role for CYP against hyperoxic lung injury. In this regard, it is interesting that the premature infants in this clinical trial who received cimetidine had higher levels of $\mathrm{F}_{2}$-isoprostanes in TA fluid than those who received the placebo (Table 6).

In the study demonstrating that cimetidine reduces hyperoxic lung injury, lambs were exposed to near $100 \%$ concentrations of inspired oxygen (1). In this clinical trial, infants in the cimetidine group were being ventilated with only $49 \pm$ $18 \%$ oxygen. It is possible that some of the difference in response to cimetidine between full-term healthy lambs and premature infants with pulmonary insufficiency could be related to differences in intensity of oxygen exposure.

A cimetidine effect limited to the most immature infants might have been obscured by including infants with birth weights as great as $1250 \mathrm{~g}$. When the analysis was limited to
Table 6. Tracheal aspirate markers

\begin{tabular}{clcc}
\hline & \multicolumn{1}{c}{ Cimetidine } & Placebo \\
\hline $\begin{array}{c}\mathrm{F}_{2} \text {-isoprostanes } \\
(\mathrm{pg} / \mathrm{mL})\end{array}$ & Baseline & $192(28-847)$ & $146(45-1510)$ \\
& & & \\
& D 4 & $24(0-240)^{*}$ & $16(0-66)$ \\
EET $(\mathrm{ng} / \mathrm{mL}) \dagger$ & D 10 & $23.5(3-331)^{*}$ & $13(0-29)$ \\
$\mathrm{IL}-8(\mathrm{pg} / \mathrm{mL})$ & Baseline & $3.00(0.15-25.17) \ddagger$ & $2.59(0.19-42.01) \S$ \\
& D 4 & $2.00(0-12.98)$ & $1.25(0-17.45)$ \\
& D 10 & $4.11(0-72.80) \|$ & $1.60(0-29.78)$ \\
$\mathrm{LTB}_{4}(\mathrm{pg} / \mathrm{mL})$ & Baseline & $133(0-761)$ & $127(0-678)$ \\
& D 4 & $35(0-508)$ & $0(0-311)$ \\
& D 10 & $37(0-1098)$ & $9.5(0-1539) \S$ \\
$\mathrm{Nucleated} \mathrm{cells}$ & Baseline & $0.32(0.13-4.75)$ & $0.32(0.07-2.13)$ \\
$\left(\times 10^{6} / \mathrm{mL}\right)$ & & & \\
& D 4 & $0.50(0.08-2.76)$ & $0.42(0.05-2.10)$ \\
& D 10 & $0.53(0.06-2.56)$ & $0.30(0.03-1.73)$ \\
\hline
\end{tabular}

Results expressed as median (range). Except as noted, $n=41,30$, and 24 for the cimetidine group at baseline, $\mathrm{d} 4$, and $\mathrm{d} 10$, and $n=42,28$, and 21 for the placebo group on these days, respectively.

$* p<0.05$ compared with placebo group.

$\dagger$ Sum of 8,9-, 11,12-, and 14,15-EET.

$\ddagger n=18 ; \S n=20 ; \| n=23$.

patients weighing less than $750 \mathrm{~g}$ at birth, no differences between study groups in any of the outcome variables shown in Table 4 were seen (data not shown).

This study does not exclude the possibility that a longer course of cimetidine treatment might have resulted in differences in the RII that were not present earlier on $\mathrm{d} 4$ or 10 . However, this trial was designed to assess the short-term effects of cimetidine as seen in the lamb study (1), reasoning that long-term effects would be unlikely in the absence of earlier short-term effects. It is also possible that an effect of cimetidine on EET production might have been seen if we had measured these products in TA fluid on $\mathrm{d} 1$ and 10 as well as d 4. However, we were able to make these measurements at only one time point because of cost and laboratory resource limitations. We made these measurements on $\mathrm{d} 4$ to correspond with the time that the protective effect of cimetidine was seen in lambs (1).

There were more deaths by 36 wk PMA in the cimetidine group and more infants in this group had IVH of any severity, or severe IVH (grade 3 or 4), but none of these differences was statistically significant (Table 5). In a post hoc analysis, however, the combined outcome of death or severe IVH was 
more frequently observed in the cimetidine group than in the placebo group (37\% versus $9 \%$ ), a difference that was statistically significant $(p<0.01)$. Among 14 patients with a cranial ultrasound study before study entry, 7 had IVH and 5 of these were in the cimetidine group. But even when these seven patients were excluded, the combined outcome of death or severe IVH was still more frequent in the cimetidine group, $28 \%$ versus $7 \%$, a difference which remained statistically significant $(p<0.05)$.

There is no ready explanation for the increase in death or severe IVH in the cimetidine group. The age at death and its cause were similarly distributed between the two study groups (data not shown). There was no difference in cimetidine plasma levels between patients who died or had severe IVH and those who did not (data not shown).

Remarkably few adverse effects are reported in newborn infants treated with this drug. Cimetidine-associated cholestatic jaundice has been reported in five children between 1 and 5 y old with peptic ulcer disease, two with preexisting biliary disease (31). In this clinical trial we found no difference between the two study groups in total serum bilirubin levels after $10 \mathrm{~d}$ postnatal age (Table 5). Even though cimetidine is a CYP inhibitor, it does not appear to attenuate cortisol response to corticotropin (32). Although treatment with $\mathrm{H}_{2}$ blockers has been associated with an increased incidence of nosocomial infections in premature infants (33), the incidence of sepsis and antibiotic usage was not different between the cimetidine and placebo groups in this study (Table 5). It has been proposed that a contractile mechanism in the ductus arteriosus involves a CYP reaction (34), but the difference in incidence of symptomatic PDA requiring indomethacin or ligation between the cimetidine group (29\%) and the placebo group (14\%) was not statistically significant.

An interesting finding in this study was the decreasing levels of $\mathrm{F}_{2}$-isoprostanes and $\mathrm{LTB}_{4}$ in TA fluid over time that was not related to study group assignment. Typically, inflammatory markers would be expected to increase over the first 7-10 d after birth such as seen with IL-8 in this study. The decrease in $\mathrm{F}_{2}$-isoprostanes and $\mathrm{LTB}_{4}$ would be consistent with decreasing oxidant stress and/or increasing antioxidant capacity, but it is not clear from this study why these changes were not also seen with IL-8.

Based on the results of this trial, we conclude that cimetidine does not reduce early lung injury in human premature infants at risk for CLD. It is possible that the effect of cimetidine observed in lambs was not seen in this study because of species and developmental differences in regard to CYP isoforms expressed in lung tissue, their susceptibility to inhibition by cimetidine, and their potential to metabolize arachidonic acid. It is also possible that factors other than oxygen exposure in critically ill, ventilator-dependent premature infants obscured any beneficial cimetidine effect that might have been present. Any causal relationship between cimetidine and the increased incidence of severe IVH or death seen in this study remains to be determined.

The need to terminate this study before reaching an enrollment sufficient to satisfy the desired statistical power weakens the overall inference that cimetidine has no beneficial effect in this clinical context. It also leaves open important questions about significant adverse effects of this drug.

Acknowledgments. The authors thank Dr. Robert A. Parker and Dr. Beverly G. Mellen for the valuable advice regarding study design and data analysis. We also thank are Dr. William Walsh, Dr. Håkan Sundell, Dr. Daniel Lindstrom, and Dr. Beverly Mellen for their service on the oversight committee.

\section{REFERENCES}

1. Hazinski TA, France M, Kennedy KA, Hansen TN 1989 Cimetidine reduces hyperoxic lung injury in lambs. J Appl Physiol 67:2586-2592

2. Hazinski TA, Noisin E, Hamon I, DeMatteo A 1995 Sheep lung cytochrome P450IA1 (Cyp1A1): cDNA cloning and transcriptional regulation by oxygen tension. J Clin Invest 96:2083-2089

3. Thibeault DW, Downing G, Reddy N, Sonderfan AJ, Parkinson A 1991 Oxygeninduced lung damage in newborn rats, potentiated by 3 -methylcholanthrene, a P-450 inducer, and lack of protection by cimetidine, a P-450 inhibitor. J Pharmacol Exp Ther 259:444-451

4. Sakai H, Okamoto T, Yamamoto R, Sindhu RK, Kikkawa Y 1992 Suppressive effect of interleukin-1 on pulmonary cytochrome $\mathrm{P} 450$ and superoxide anion production. Biochem Biophys Res Commun 185:1083-1090

5. Bysani GK, Kennedy TP, Ky N, Rao NV, Blaze CA, Hoidal JR 1990 Role of cytochrome P-450 in reperfusion injury of the rabbit lung. J Clin Invest 86:1434 1441

6. Granville DJ, Tashakkor B, Takeuchi C, Gustafsson AB, Huang C, Sayen MR, Wentworth P Jr., Yeager M, Gottlieb RA 2004 Reduction of ischemia and reperfusion-induced myocardial damage by cytochrome P450 inhibitors. Proc Natl Acad Sci U S A 101:1321-1326

7. Morrow JD, Awad JA, Kato T, Takahashi K, Badr KF, Roberts LJ 2nd, Burk RF 1992 Formation of novel non-cyclooxygenase-derived prostanoids $\left(\mathrm{F}_{2}\right.$-isoprostanes $)$ in carbon tetrachloride hepatotoxicity. An animal model of lipid peroxidation. J Clin Invest 90:2502-2507

8. Gonder JC, Proctor RA, Will JA 1985 Genetic differences in oxygen toxicity are correlated with cytochrome P-450 inducibility. Proc Natl Acad Sci U S A 82:63156319

9. Todd NW, Hunt CM, Kennedy TP, Piantadosi CA, Whorton AR 1992 Effects of inhibition and induction of cytochrome P-450 isozymes on hyperoxic lung injury in rats. Am J Respir Cell Mol Biol 7:222-229

10. Omiecinski CJ, Aicher L, Swenson L 1994 Developmental expression of human microsomal epoxide hydrolase. J Pharmacol Exp Ther 269:417-423

11. Nebert DW, Russell DW 2002 Clinical importance of the cytochromes P450. Lancet 360:1155-1162

12. Nelson DR, Zeldin DC, Hoffman SM, Maltais LJ, Wain HM, Nebert DW 2004 Comparison of cytochrome P450 (CYP) genes from the mouse and human genomes, including nomenclature recommendations for genes, pseudogenes and alternativesplice variants. Pharmacogenetics 14:1-18

13. Zeldin DC 2001 Epoxygenase pathways of arachidonic acid metabolism. J Biol Chem 276:36059-36062

14. Capdevila JH, Falck JR 2001 The CYP P450 arachidonic acid monooxygenases: from cell signaling to blood pressure regulation. Biochem Biophys Res Commun 285:571-576

15. Kroetz DL, Zeldin DC 2002 Cytochrome P450 pathways of arachidonic acid metabolism. Curr Opin Lipidol 13:273-283

16. Shenai JP, Mellen BG, Chytil F 2000 Vitamin A status and postnatal dexamethasone treatment in bronchopulmonary dysplasia. Pediatrics 106:547-553

17. Cotton RB, Haywood JL, FitzGerald GA 1991 Symptomatic patent ductus arteriosus following prophylactic indomethacin. A clinical and biochemical appraisal. Biol Neonate 60:273-282

18. Papile LA, Burstein J, Burstein R, Koffler H 1978 Incidence and evolution of subependymal intraventricular hemorrhage: a study of infants with weights less than 1500 grams. J Pediatr 92:529-534

19. Lloyd CW, Martin WJ, Taylor BD 1985 The pharmacokinetics of cimetidine and metabolites in a neonate. Drug Intell Clin Pharm 19:203-205

20. Ziemniak JA, Wynn RJ, Aranda JV, Zarowitz BJ, Schentag JJ 1984 The pharmacokinetics and metabolism of cimetidine in neonates. Dev Pharmacol Ther 7:30-38

21. Aranda JV, Outerbridge EW, Schentag JJ 1983 Pharmacodynamics and kinetics of cimetidine in a premature newborn. Am J Dis Child 137:1207

22. Xu K, Arora VK, Chaudhary AK, Cotton RB, Blair IA 1999 Quantitative analysis of cimetidine in human plasma using LC/APCI/SRM/MS. Biomed Chromatogr 13:455-461

23. Morrow JD, Roberts LJ 2nd 1994 Mass spectrometry of prostanoids: $F_{2}$-isoprostanes produced by non-cyclooxygenase free radical-catalyzed mechanism. Methods Enzymol 233:163-174

24. Zeldin DC, Plitman JD, Kobayashi J, Miller RF, Snapper JR, Falck JR, Szarek JL, Philpot RM, Capdevila JH 1995 The rabbit pulmonary cytochrome P450 arachidonic acid metabolic pathway: characterization and significance. J Clin Invest 95:2150 2160

25. Levine M, Law EY, Bandiera SM, Chang TK, Bellward GD 1998 In vivo cimetidine 
inhibits hepatic CYP2C6 and CYP2C11 but not CYP1A1 in adult male rats. J Pharmacol Exp Ther 284:493-499

26. Seubert J, Yang B, Bradbury JA, Graves J, Degraff LM, Gabel S, Gooch R, Foley J, Newman J, Mao L, Rockman HA, Hammock BD, Murphy E, Zeldin DC 2004 Enhanced postischemic functional recovery in CYP2J2 transgenic hearts involves mitochondrial ATP-sensitive $\mathrm{K}+$ channels and p42/p44 MAPK pathway. Circ Res 95:506-514

27. Node K, Huo Y, Ruan X, Yang B, Spiecker M, Ley K, Zeldin DC, Liao JK 1999 Anti-inflammatory properties of cytochrome P450 epoxygenase-derived eicosanoids. Science 285:1276-1279

28. Moorthy B, Parker KM, Smith CV, Bend JR, Welty SE 2000 Potentiation of oxygen-induced lung injury in rats by the mechanism-based cytochrome P-450 inhibitor, 1-aminobenzotriazole. J Pharmacol Exp Ther 292:553-560

29. Moorthy B, Nguyen UT, Gupta S, Stewart KD, Welty SE, Smith CV 1997 Induction and decline of hepatic cytochromes P4501A1 and 1A2 in rats exposed to hyperoxia are not paralleled by changes in glutathione S-transferase-alpha. Toxicol Lett $90: 67-75$
30. Sinha A, Muthiah K, Jiang W, Couroucli X, Barrios R, Moorthy B 2005 Attenuation of hyperoxic lung injury by the CYP1A inducer $\{$ beta $\}$-naphthoflavone. Toxicol Sci $87: 204-212$

31. Lilly JR, Hitch DC, Javitt NB 1978 Cimetidine cholestatic jaundice in children J Surg Res 24:384-387

32. Spapen H, Diltoer M, Nguyen DN, Ingels G, Ramet J, Huyghens L 1995 One week treatment with cimetidine does not attenuate the cortisol response to a short corticotropin test in stable intensive care patients: a prospective, randomized, and controlled study. Acta Anaesthesiol Belg 46:133-140

33. Rojas MA, Efird MM, Lozano JM, Bose CL, Rojas MX, Rondon MA, Ruiz G, Pineros JG, Rojas C, Robayo G, Hoyos A, Gosendi MH, Cruz H, O'Shea M, Leon A 2005 Risk factors for nosocomial infections in selected neonatal intensive care units in Colombia, South America. J Perinatol 25:537-541

34. Coceani F, Kelsey L, Seidlitz E, Korzekwa K 1996 Inhibition of the contraction of the ductus arteriosus to oxygen by 1-aminobenzotriazole, a mechanism-based inactivator of cytochrome P450. Br J Pharmacol 117:1586-1592 